\title{
Effect of Artificial Insemination on different production parameter in Hubbard classic broiler parent stock
}

\author{
M. Habibullah*, M. A. Hashem, M. S. Rana and M. H. Islam \\ Department of Animal Science, Bangladesh Agricultural University, Mymensingh-2202, Bangladesh \\ *E-mail: habib_rumon@rocketmail.com
}

\begin{abstract}
The experiment was conducted to determine the effect of artificial insemination (Al) on different production parameter in Hubbard Classic Broiler breeder parent stock. A total number of 300 female and 30 male Hubbard Classic broiler breeder parent stock birds were used as experimental animals and parameter recorded are: Health condition and body weight of birds, $\%$ of Production, $\%$ Hatchability, $\%$ Uniformity, grade A chicks, mortality $\%$, hatching egg $\%$ \& effect of diluents use, birth weight of day old chick (DOC). Significant variation $(p<0.01)$ was observed in number of hatched birds, \% of hatchability, production of total no of Grade A chicks, total number of damaged chicks and average chick weight. In the study, hatchability (\%), production (\%), growth and puberty weight (g) were significantly higher during post insemination compared to pre insemination stage, where as mortality (\%) and uniformity (\%) were significantly lower in case of post insemination stage. Body weight and uniformity (\%) of birds either both sexes were significantly $(p<0.01)$ different in birds at pre insemination stage compared to the birds at insemination. To be mentioned that body weight of birds was negatively correlated to the uniformity. Finally it could be concluded that $\mathrm{Al}$ may be better in all the parameters observed in this study than natural mating. So, Al can be practiced in Hubbard Classic broiler breeder parent stock.
\end{abstract}

Keywords: Artificial Insemination, Broiler breeder, Hatchability, Egg production, Body weight

\section{Introduction}

Poultry is the most vital and prominent industry for economic development in Bangladesh. There was a time when poultry was reared in backyard system and considered as a small and part-time income for the rural people. Now standing at the doorstep of $21^{\text {st }}$ century, there are many commercial sectors, which make the globalization concept for work and strengthening the future economical structure and undoubtedly, poultry to be one of the most effective and active one (Das, 2009). There are more than 270 hatcheries in Bangladesh with a total strength of approximately 1350 lacks parent stock/week and producing approximately 650 cores of day old chicks annually (Rahman, 2009).

Broiler breeder production is one of the profitable production activities as like as commercial hybrid broiler and layer production in Bangladesh. Producing broiler breeder is also more remunerative than commercial broiler (Farooq et al., 2001; Asghar et al., 2000 and Farooq et al., 2003). The parent growers are interested to select strain well adapted to local condition, and inheritance capacity for producing quality hatching egg is given prime consideration (Hossain et al., 2005). The recent development indicates that the number of parent stock farms and parent birds are increasing in Bangladesh day by day. Through the number of farms and birds are increasing competitively, the management technologies and other necessary information are not available to the farmers which may affect the performance of broiler parents. The performance data particularly the effect of parent body weight on reproductive performance under Bangladesh conditions are lacking. The commercial producers, who are maintaining broiler parent stocks, develop their management techniques mostly on the basis of past experience and very limited farmers collect data permanently.

Bodyweight and body condition at a time of maturity probably have the significant and biggest influence on future breeder performance. Optimum breeder performance results following successful growing management. By controlling body weight, the rearing broiler breeder reach sexual maturity with good body fleshing but not with excessive fat deposition. Relationship between the weight of broiler breeder and level of production has received considerable and well deserved attention. Today it is generally acknowledged that if breeder gains too much weight too quickly, they control of their reproductive processes. Body weight also effect egg weight, fertility and hatchability of breeders. The larger birds lay eggs which are bigger in size than the smaller one. At the onset of laying the eggs become smaller and 
then increasing in size with the increasing age. Robinson (1996) reported that body weight was associated with significant reduction in the hatching eggs. The excess weight hinders the ability of female to complete successful mating. Problems of relative size between male and female are common in over weight birds. It is also proven that over weight females has a diminished capacity for sperm storage, since sperm storage glands are surrounded and contracted by fat and there are also globules present internally. Hocking and Bernared (1997) outlined that lower fertility was associated with greater weight of breast muscle, lower frequency of observed copulation and high number of incomplete mating. Age also is an important factor that affects hatchability of eggs. Normally, the fertility of pullet eggs is more than the aged hens.

To increase poultry production different types of reproductive and management technologies are used. Artificial Insemination (AI) in poultry is a process by which semen is collected from male birds \& then introduces to female for the purpose of fertilizing eggs. For good hatchability and rapid genetic gain, the following factors need to be considered. To place the required dose of semen into the oviduct of the female so that it is deposited near the sperm storage tubules. A cock can fertilize 6-10 hens in a flock. But in case of artificial insemination it is claimed this ratio could be increased fourfold. In case of artificial insemination from 6-8 males' semen can be inseminated 150-170 females. Use of older males from outstanding performance, laying cages can be used, successful cross breeding. From the above condition artificial insemination could be a solution for fertility problem. With the above discussion, present study was conducted with the objectives of examining the effect of artificial insemination \& to know the different production parameter in Hubbard Classic broiler parent stock pre \& post insemination.

\section{Materials and Methods}

\section{Study area, period and experimental birds}

The experiment was conducted at the Paragon Chamiadi Project, Valuka, Mymensingh from April 2011 to May 2012. A total number of 300 female and 30 male Hubbard Classic broiler breeder parent stock birds were maintained and used as experimental animals, which were collected from the Paragon GP Hatchery, Moulovibazar, Sylhet

\section{Management Procedure}

For Al the birds were reared in controlled shed in cage system. In this system, each male bird was kept in an individual cage whereas two hens were kept in one cage.Female birds were provided with starter, grower, prebreeder \& finally breeder ration and broiler parent male ration (BPM) was provided to the male bird.

From 300 birds half were reared in Cage \& done artificial insemination. The rest were keeping in floor and natural mating occurs.

\section{Selection of male}

For selection of males following points were considered: \# Male must already have reached maturity \# Have no physical defects and be healthy \# The males are sexually active \# Tame and free from any external parasites \# Not terrified when restrained or handled \# Kept apart from, but preferably in sight of females.

\section{Selection of female}

Following points were considered for selection of female: \# must be in production or the birds not in injured \# Having a hard shelled eggs in lower part of hen oviduct so the sperm can move easily to the area where it unites with the ova.

Oviduct has five parts- $1^{\text {st }}$ is Infundibulum. When a mature Ovum is released from the Ovary, ovum spends about 15-18 minutes in Infundibulum. When artificial insemination is done the sperm makes its way to the infundibulum where it awaits the release of an ovum. Sperm can live in the infundibulum for more than 2 weeks. So the ovum is released from the ovary into the infundibulum where it is fertilized with the rooster's sperm if the hen has been mated or insemination done. 


\section{Semen collection}

Collection of semen was done by abdominal massage method. Semen was collected twice in a week. When insemination sperm enter the hen's oviduct and stored within sperm storage glands. Sperm can remain alive in these glands and fertilize eggs for up to 3 weeks. But we collect \& inseminate twice in a week to produce excellent fertility that has been found $90-95 \%$.

After collection of semen sometime add extender/diluents to maintain the viability of the sperm \& maximize the number of hens that can be inseminated by increasing the volume. Poultry semen is generally viscose, highly concentrated and contains billions of sperm $/ \mathrm{ml}$, and thus needs to be diluted for Al purpose (Donoghue \& Wishart, 2000). The composition of diluents were Sodium Chloride $(\mathrm{NaCl})=68$ $\mathrm{gm}$, Potassium Chloride $(\mathrm{KCl})=17.33 \mathrm{gm}$, Calcium Chloride $\left(\mathrm{CaCl}_{2}\right)=6.42 \mathrm{gm}$, Magnesium Chloride $\left(\mathrm{MgCl}_{2}\right)=2.50 \mathrm{gm}$, Sodium bicarbonate $=24.50 \mathrm{gm}$, Distilled water $=10000 \mathrm{ml}$. Name of extender is Beltsville poultry semen extender. Normally the ratio of added diluents is (semen: diluents) $=(1: 1)$

\section{Insemination procedure}

For insemination pressure was applied to the left side of the abdomen around the vent, which caused the cloaca to avert and the oviduct to procedure protrude. A syringe or plastic straw was inserted into the oviduct and $.02 \mathrm{cc}$ of diluted semen is derived with 1-2 million sperm concentration. As the semen expelled by the inseminator, pressure around the vent was released, this assisted the hen in relating sperm in the vagina or the oviduct.

Equipments were used for artificial insemination

- Al Gun (2 ml Syringe used for Insemination)

- Glass Pipe

- $2 \mathrm{ml}$ Syringe attached with Rubber Tube

- $2 \mathrm{ml}$ Syringe attached with Glass Pipe

- Semen Collecting Funnel (9-11 ml)

- Diluents

- Gloves

\section{Egg collection and incubation}

Artificial insemination (Al) day was recorded as day 0 of fertilization in the hen. After a single insemination, eggs were collected daily from the $2^{\text {nd }}$ day post insemination. All eggs were collected 5 times in a day. After collection grading of the eggs were done. After grading fumigation of the eggs was completed and stored the eggs in egg store room where temperature was between $16-18{ }^{\circ} \mathrm{C}$, prior to incubation. Cracked and dirty eggs were not incubated and were discarded. On the $18^{\text {th }}$ day of incubation all eggs were candled, to identify the fertile eggs. Only fertile eggs were transferred from setter to hatchers in the hatchery for a period of 3 days. The fertility, number of hatched and dead chicks were counted and recorded.

\section{Statistical analysis}

All the data were recorded on selected male and female birds as per experimental design. Collected data were analyzed by paired sample t test using SPSS-17 version computer package.

\section{Results and Discussion}

\section{Health condition of male and female birds during natural mating and artificial insemination}

Table 1 shows that health condition of male birds and female birds during Artificial Insemination (AI) and the health condition before AI. There was significant variation $(p<0.01)$ in male body weight, female body weight, uniformity $\%$ of male birds and the uniformity $\%$ of female birds before and during Al. 
Table 1. Health condition of male and female birds before and during Al

\begin{tabular}{|c|c|c|c|c|}
\hline Health parameters & Condition & Mean & Std. Devi & Sig. \\
\hline \multirow{2}{*}{ Male (bwt) } & Pre Insemination & 4069.00 & 103.33 & \multirow{2}{*}{ ** } \\
\hline & During Insemination & 4353.50 & 163.80 & \\
\hline \multirow{2}{*}{ Female (bwt) } & Pre Insemination & 3533.50 & 39.42 & \multirow{2}{*}{ ** } \\
\hline & During Insemination & 3714.00 & 66.05 & \\
\hline \multirow{2}{*}{ Male (Uniformity \%) } & Pre Insemination & 98.00 & 1.79 & \multirow{2}{*}{ ** } \\
\hline & During Insemination & 96.00 & 3.85 & \\
\hline \multirow{2}{*}{ Female (Uniformity \%) } & Pre Insemination & 97.50 & 1.05 & \multirow{2}{*}{ ** } \\
\hline & During Insemination & 94.00 & 2.53 & \\
\hline
\end{tabular}

** Significant at 1\% level $(p<0.01), A l=$ Artificial Insemination, bwt= Body Weight

From the data we also show that when body weight is high, uniformity is low and when body weight was low uniformity was high. This is supported by the report of Schramm (2005) when Artificial Insemination was practiced body weight increased and uniformity of the male and female bird was decreased. Similar result was reported by Karaca et al., (2002).

\section{Effect of Al on different production parameters}

Table 2 shows the effect of Al on different production parameters. Significant variation $(p<0.01)$ was observed in- $\%$ of hatchability, production $\%$, total mortality $\%$, uniformity $\%$ and puberty weight (gm) of the birds after Al than before. In this study, hatchability \%, production $\%$, and puberty weight were significantly higher after Al than before Al. On the other hand, mortality $\%$ and uniformity $\%$ were significantly lower after Al than before Al.

Table 2. Effect of AI on different production parameters

\begin{tabular}{|c|c|c|c|c|}
\hline Parameters & Condition & Mean & Std. Deviation & Sig. \\
\hline \multirow[t]{2}{*}{ Hatchability \% } & Pre insemination & 71.45 & 1.80 & \multirow{2}{*}{ ** } \\
\hline & Post insemination & 79.30 & 3.82 & \\
\hline \multirow[t]{2}{*}{ Production \% } & Pre insemination & 71.75 & 6.72 & \multirow{2}{*}{ ** } \\
\hline & Post insemination & 72.80 & 7.46 & \\
\hline \multirow[t]{2}{*}{ Mortality \% } & Pre insemination & 21.50 & 6.61 & \multirow{2}{*}{$\star \star$} \\
\hline & Post insemination & 14.75 & 4.03 & \\
\hline \multirow[t]{2}{*}{ Puberty (wt) } & Pre insemination & 46.48 & 0.76 & \multirow{2}{*}{ ** } \\
\hline & Post insemination & 46.63 & 3.07 & \\
\hline \multirow[t]{2}{*}{ Uniformity \% } & Pre insemination & 97.25 & 1.26 & \multirow{2}{*}{$\star *$} \\
\hline & Post insemination & 95.25 & 2.99 & \\
\hline
\end{tabular}

** Significant at $1 \%$ level $(p<0.01)$

In this study $\%$ of hatchability, production $\%$, body weight and puberty weight were significantly higher in post insemination than pre insemination. On the other hand $\%$ of total mortality, uniformity was significantly lower in post insemination than pre insemination. We found same result from Sayyazadeh et al. (2005) the average of hatchability percentage in natural mating for Arian and Ross 308 lines were 82.7 and 83.1 respectively. But when artificial insemination has done, these values were increased and that was $87.2 \%$ and $89.4 \%$ respectively. The test show that hatchability percentage increased by artificial insemination. The similar result also observed by the Hocking and Bernared (1997), Christensen (2001) and Surai et al., (1996).Robinson (1996) reported that when artificial insemination practiced hatchability and production percentages are increased compare to natural mating.

The result was similar with Schramm (2005) the development of suitable methods to collect sperm as well as insemination, dilution and preservation of sperm has resulted to a useful and significant method in poultry breeding. This method of mating is done in the breeding of laying hens, guinea fowls and carina moschata, but it has the most important role in the reproduction of modern heavy lines of turkeys. 
Because of $\mathrm{Al}$, it is possible to increase the proportion of mating, store semen from 6 to $24 \mathrm{~h}$ and longer without any loss of fertility and perform semen transfer. It is also possible to arrange semen depots for genetic resources by deep freezing conservation. The manual work and the need for weekly repetition of Al to achieve satisfactory results of fertility (90 to 95\%) have resulted to the rampant use of Al in poultry. Artificial inseminations also increase production and puberty weight, but decrease mortality $\%$ and uniformity $\%$ of the birds.

\section{Effect of Al on different production parameters at two age group of Hubbard Classic female parent stock}

Table 3 shows that Effect of Al on different production parameters at 28 and 62 weeks of age. It appears that significant variation $(p<0.01)$ was observed in number of hatched birds, $\%$ hatchability, production of grade A chicks, damaged chicks, and the average chicks weight. Number of hatched birds, \% of hatchability, grades A chicks were significantly higher in 28 weeks of age. These parameters are lower in 62 week of age. But number of damaged chicks and chicks' weight were significantly lower in 28 weeks of age where in 62 week of age these are higher.

Table 3. Effect of Al on different production parameters 28 and 62 weeks of age of Hubbard Classic female parent stock

\begin{tabular}{|c|c|c|c|c|}
\hline Parameters & Condition & Mean & Std. Dev. & Sig. \\
\hline \multirow{2}{*}{ Number of hatched bird } & At 28 week & 24360 & 110 & \multirow{2}{*}{ ** } \\
\hline & At 62 week & 23203 & 102 & \\
\hline \multirow{2}{*}{ Hatchability \% } & At 28 week & 87.8 & 0.2 & \multirow{2}{*}{ ** } \\
\hline & At 62 week & 78.9 & 0.1 & \\
\hline \multirow{2}{*}{ Grade A chicks } & At 28 week & 24100 & 50 & \multirow{2}{*}{ ** } \\
\hline & At 62 week & 22317 & 45 & \\
\hline \multirow{2}{*}{ Damage no of chicks } & At 28 week & 60 & 2 & \multirow{2}{*}{ ** } \\
\hline & At 62 week & 75 & 5 & \\
\hline \multirow{2}{*}{ Chick wt(gm) } & At 28 week & 44.5 & 0.5 & \multirow{2}{*}{ ** } \\
\hline & At 62 week & 46 & 1 & \\
\hline
\end{tabular}

** Significant at $1 \%$ level $(P<0.01)$

Gumuka et al., (2005) reported that highest value of fertility, hatchability in artificial insemination in 30 week of age. But in the age after 58 week, the fertility and hatchability was decreased. Similar result from Islam et al., $(2008)$ highest $(\mathrm{P}<0.05)$ hatchability was found in the age group between 31 to 60 weeks (77.99\%) followed by 61weeks (75.49\%). The same result also observed by the Pramunik (2009) and Tuncer et al. (2006).

\section{Effect of diluents on hatchability of Hubbard Classic parent stock}

From the table it appears that significant variation $(p<0.01)$ exists between the Al performed using diluted semen and Al without diluents. The hatchability \% was significantly higher in Al performed using diluted semen compared to undiluted one. Diluents maintenance of $\mathrm{pH}$, osmolarity and provide energy for the sperm. The motility and metabolic rate of sperm depend on $\mathrm{pH}$. When $\mathrm{pH}$ reduces the sperm motility reduces and a high $\mathrm{pH}$ increases the metabolic rate (Donoghue \& Wishart, 2000).

Table 4. Shows that Effect of diluents on hatchability of Hubbard Classic parent stock

\begin{tabular}{|l|c|c|c|}
\hline Use of diluents & Mean & Std. Devi. & Sig. \\
\hline Diluted Semen & 86.14 & 2.32766 & \multirow{2}{*}{$* *$} \\
\hline Un Diluted Semen & 81.4 & 3.48353 & \\
\hline
\end{tabular}

** Significant at $1 \%$ level $(P<0.01)$ 
The present result of hatchability is similar to Rahimi et al. (2001) this indicates that good semen diluents is of high importance in Al application in order to maintain the semen in optimum condition. In this study, the effect of 3 different kinds of semen extenders such as Sexton (American), IMV (French), and TMU (Iranian semen extender developed in this research) were compared based on the semen quality. The semen diluted by Sexton extender showed better quality than that diluted by the other 2 extenders $(P>0.05)$. No differences were observed between IMV and TMU in their effects on semen quality. Method of semen storage also had significant effect on motility and viability of spermatozoa $(P<0.05)$. Liquid and frozen form of maintaining semen showed significant effects on sperm quality $(P<0.01)$. Duration of sperm storage affected the motility and viability of spermatozoa $(P<0.01)$. Application of Al immediately after dilution of fresh semen showed better results. The kind of extender and method of sperm storage affected the rate of fertility and hatchability in broiler breeder hens $(P<0.01)$.

\section{Effect of Al and Natural Mating on hatching egg production (\%)}

Table 5 shows that effect of $\mathrm{Al}$ and natural mating on hatching egg production (\%). There was no significant difference $(p>0.05)$ which shown in the table between hatching egg production $\%$ in natural mating and artificial insemination. From Sayyazadeh et al. (2005) we show that artificial insemination significantly made thinner eggshell and decreased average weight egg of the lines $(p<0.05)$. Besides, artificial insemination increased bi-yolk egg production percentage and in general non standard eggs production in the lines. The percentage of losses during production in this case was greater than with natural mating, compared to control tester.

Table 5. Effect of Al and Natural Mating on hatching egg production (\%)

\begin{tabular}{|l|c|c|c|}
\hline Mating system & Mean & Std. Devi. & Sig. \\
\hline Natural mating (32 wks) & 95.50 & 3.13 & \multirow{2}{*}{ NS } \\
\hline Al (32 wks) & 95.00 & 2.88 & \multirow{2}{*}{ NS } \\
\hline Standard (Natural mating) & 92.00 & 0.76 & 1.33 \\
\hline Standard (Al) & 92.00 & & \\
\hline
\end{tabular}

NS=Non-Significant, Std=Standard of Hatchability

\section{Summary and Conclusion}

In this study, percent of hatchability, production and weight of growth and puberty were significantly higher in post insemination than pre insemination. On the other hand, percent of mortality and uniformity were significantly lower post insemination than pre insemination. There was no significant difference in hatching egg production for artificial insemination \& natural mating. There was significant variation $(p<0.01)$ in body weight of male and female, uniformity $\%$ of male and female birds before and during Al. In case of higher body weight, uniformity was found to be lower and for lower body weight uniformity was higher. Finally it could be concluded that Al can be practiced in Hubbard Classic broiler breeder parent stock to improve different production parameters.

\section{References}

Asghar, A. Farooq, M. Mian, M.N. and Khurshid, A. 2000. Economics of broiler production in Mardan division. Journal. of Rural Development Administration.32: 56-64.

Christensen, V.L. 2001. Factors associated with early embryonic mortality. World Poultry Science Journal. 57: 359-372.

Das, C. 2009. Performance of Broiler parent stock in relation to growth target and feed allocation. MS Thesis, Department of Poultry Science. Bangladesh Agricultural University. Mymensingh.

Donoghue, A.M. and Wishart, G.J. 2000. Storage of poultry semen. Animal Reproductive Science. New York Academic Press.62: 213-232.

Farooq, M., Haq, Z.U., Mian, M.A., Durani, F.R. and Sayed, M. 2003. Cost of production, gross return and net profit in commercial egg production. Pakistan Veterinary Journal. 23: 41-48.

Gumuka, M. Kapkowska, W. 2005. Age effect of broiler breeders on fertility and sperm penetration of the perivitelline layer of the ovum. Animal Reproduction. Science. 90: 135-148. 


\section{Habibullah et al.}

Hocking, M. and Bernared, A.C. 1997. The influence of day length, body weight and age on the production ability of breeder cockerels. World Poultry Science J. 63: 1705-1710.

Hossain, M.E. Chowdhury, S.D., Ahammed, M., Pramanik, M.A.H. and Rahman, M.R. 2005. Growth performance of Kasila broiler parent stock reared on quantitative feed restriction, under Bangladesh condition. International Journal of Poultry Science.4: 153-158.

Islam, S.S. Hossain, M.B. and Khan, M.K.A. 2008. Effect of genotype, age and season on hatchability of egg. Bangladesh. J. Animal Sci. 37 (1): $17-22$.

Karaca, A.G. Parker, H.M. and McDaniel, C.D. 2002. Elevated body temperature directly contributes to heat stress infertility of broiler breeder males. World Poultry Science J. 81: 1892-1897.

Pramunik, A.H. 2009. Effect of body weight, maturity production performance, fertility and hatchability of broiler parent stock. MS Thesis. Department of Poultry Science. Bangladesh Agricultural University. Mymensingh.

Rahimi, S. Mohammadi, R. Shahidi, R. Salehi, M. Jomeh, Z. 2001. Factors associated with early embryonic mortality. Journal of Faculty of Veterinary Medicine, University of Tehran. 56(3): 23-28.

Rahman, M. 2009. Poultry farming in Bangladesh present and future. Proceeding of the World Poultry Science Association, Bangladesh Branch. pp: 38-41.

Robinson. 1996. Effects of short storage conditions and broiler breeder age on hatchability, hatching time, and chick weights. World Poultry Science J. 76: 1459-1466.

Schramm, G.P. 2005. Artificial insemination in poultry \& effect of diluents on Duck Semen. Rutgers University Press, New Jersey. 77: 206-215

Sayyazadeh, H. and Shahsavarani, H. 2005. Effects of Artificial Insemination on performance of broiler breeders. Department of Animal Science, Faculty of Agriculture, Mazandaran University, Sari, Iran

Surai, P.F. and Wishart, G.J. 1996. Poultry artificial insemination technology in the countries of the former USSR. World Poulty. Science. J. 52: 29-43.

Tuncer, P.B. Kinet, H. Ozdogan, N. and Demiral, O. 2006. Evaluation of some spermatological characteristics in cocks. Ankara Uni. Vet. Sci. 23: 69-74. 